\title{
ÉMILE DURKHEIM E GABRIEL TARDE: ASPECTOS TEÓRICOS DE UM DEBATE HISTÓRICO (1893-1904)
}

\author{
Emile Durkheim and Gabriel Tarde: \\ Theoretical Aspects of a Historical \\ Debate (1893-1904) \\ Marcia Consolim*
}

\begin{abstract}
RESUMO
Trata-se de apresentar alguns aspectos teóricos do debate entre Gabriel Tarde e Émile Durkheim no fim do século XIX na França. O debate, que mobilizou círculos intelectuais de ambos os lados, colocou frente a frente posições opostas em relação a aspectos tais como a concepção de solidariedade social, o valor da ciência e de sua relação com respeito a valores e fins sociais, a autonomia da sociologia em relação à psicologia e seu papel diante das ciências sociais particulares. Conclui-se que tais oposições estão ligadas a distintas concepções sobre o mundo intelectual e seu papel nas sociedades modernas.
\end{abstract}

Palavras-chave: Gabriel Tarde; Émile Durkheim; Sociologia; Psicologia.

\begin{abstract}
This article presents some theoretical aspects of the debate between Gabriel Tarde and Émile Durkheim at the end of the $19^{\text {th }}$ Century in France. The debate, which mobilized intellectual milieus from both sides, put face to face opposing standpoints related to subjects such as the concept of social solidarity, the value of science and its relationship to social values and objectives, the autonomy of sociology regarding psychology, and its role vis-à-vis specific social sciences. I conclude that these oppositions are related to different views of the intellectual world and its role in modern society.
\end{abstract}

Key-words: Gabriel Tarde; Émile Durkheim; Sociology; Psychology.

* Professora adjunta da Universidade Federal de São Paulo (UNIFESP). 
Este artigo pretende apresentar ao leitor brasileiro os principais aspectos de um debate que ficou famoso na última década do século XIX, na França, por ter envolvido autores importantes no campo dos estudos sociais do período: Gabriel Tarde (1843-1904) e Émile Durkheim (1858-1917). Esse episódio pode ser considerado clássico na história das ciências sociais, não apenas porque envolveu Durkheim, autor posteriormente considerado fundador da escola de sociologia francesa, mas também porque explicitou, por meio de disputas pela própria concepção legítima de ciências sociais ou de sociologia, polarizações estruturais ao campo intelectual da época que, em certo sentido, perduram até os dias atuais ${ }^{1}$.

O movimento de retorno dos estudiosos a esse debate, em especial na última década, está relacionado, em parte, a uma tentativa de resgatar ou de legitimar a obra de Gabriel Tarde no âmbito das ciências sociais contemporâneas, seja por seu valor para a história disciplinar, seja para torná-la paradigma de uma nova sociologia "pós-durkheimiana" ou "pós-determinista". Daí o inegável vínculo entre o debate em sua própria época e as visões sobre o debate um século depois. Este artigo se insere claramente dentro do primeiro propósito à medida que pretende realçar a importância do debate para a história da disciplina. Por outro lado, não se trata aqui de reproduzir a história do debate - seja quanto à ordem cronológica seja quanto ao escopo temático -, mas sim de selecionar algumas oposições teóricas paradigmáticas de modo a facilitar a compreensão do desenvolvimento

1 Indico os principais textos sobre o debate. KARSENTI, Bruno. "Retour sur le débat entre Durkheim et Tarde". In: CHAUVIRÉ, Christiane; OGIEN, Albert. La réegularité - habitude, disposition et savoir-faire dans l'explication. Paris: Ed. EHESS, 2002. BORLANDI, Massimo; BESNARD, Philippe. "Contre Durkheim à propos de son Suicide". In: BORLANDI, M.; CHERKAOUI, Mohamed. Le Suicide un siècle après Durkheim. Paris: PUF: 2000. BESNARD, Philippe. "Durkheim critique de Tarde: des Règles au suicide”. In: La Sociologie et sa méthode: les Règles de Durkheim un siècle après. Paris: L'Harmmatan, 1995. Este artigo foi republicado em Durkheimian Studies/Études durkheimiennes. Paris/Genéve: Droz, 2003. BORLANDI, Massimo. Informations sur la rédaction du Suicide et sur l'état du conflit entre Durkheim et Tarde de 1895 a 1897. Durkheim Studies/Études Durkheimiennes, 1994. LUKES, Steven. Émile Durkheim, su vida y su obra. Madrid: CIS e Siglo XXI, 1984 [1973]. MILLET, Jean. Gabriel Tarde et la Philosophie de l'Histoire. Paris: Vrin, 1970. PINATEL, Jean. La pensée criminologique d'Émile Durkheim et sa controverse avec Gabriel Tarde. Revue de Science Criminelle, p. 435-442, 1959. Em 2008, uma versão do debate foi elaborada por um conjunto de autores: VARGAS, Eduardo V.; LATOUR, Bruno; KARENTI, Bruno; AÏT-TOUATI, Frédérique; SALMON, Louise. The Debate Beetween Tarde and Durkheim. In: Environment and Planning D: Society and Space, v. 26, p. 761-777, 2008.

2 PINTO, Louis. Ne pas multiplier les individus inutilement. Revue Interrogations, v. 2. Trad. PULICI, Carolina; CONSOLIM, Marcia. Não multiplicar o indivíduo inutilmente. Lua Nova. Revista de Cultura e Política, Cedec, n. 77, p. 205-225, 2009. Simmel et Tarde dans les années 1900. In: Le commerce des idées philosophiques. Broissieux: Éd. du Croquant, 2009. 
posterior da disciplina. Nesse sentido, busca-se evitar avaliações sobre os argumentos e as teorias, pois o objetivo aqui não é estabelecer um "vencedor" e um "perdedor" do debate, mas sim realçar suas oposições estruturais.

Ao longo do século XX, a recepção à obra de Tarde foi mais intensa nos meios jurídicos do que sociológicos, enquanto a de Durkheim tornou-se uma referência nas faculdades de letras e de filosofia. Contudo, no período em que se deu o debate, Tarde era tão conhecido pelo público intelectual francês quanto Durkheim e, certamente, era mais prestigiado do que este em certas instâncias do poder social e intelectual ${ }^{3}$. Desse modo, importa evitar uma leitura anacrônica do debate e tratar de modo equitativo as posições teóricas de cada um dos contendores, analisando de maneira relacional suas respectivas concepções de sociologia ou de ciências sociais, uma vez que se pretende ressaltar as polarizações no que diz respeito às hierarquias disciplinares e às concepções de ciência e de método implicadas em ambas as teorias. Além disso, importa também referir o debate ao contexto intelectual da época para uma melhor compreensão das tomadas de posição de ambos os autores, tendo em vista que se trata de um momento de intensas transformações institucionais e disciplinares e de mudança de paradigmas na teoria sociológica.

Segundo balanço feito por Borlandi, o debate pode ser circunscrito a doze textos contra Tarde e a quatorze contra Durkheim, considerando-se as republicações de artigos em coletâneas ${ }^{4}$. Contudo, é possível afirmar que o

3 Cf. CONSOLIM, Marcia Cristina. Gabriel Tarde e as Ciências Sociais Francesas: afinidades eletivas. Mana - Revista de Antropologia, v. 14, n. 2, p. 269-298, 2008. Nesse artigo, assim como na tese de doutorado, desenvolvo a questão do campo intelectual no período, de modo que aqui me restrinjo a alguns aspectos teóricos do debate.

4 Os principais textos indicados por Borlandi são os seguintes. Da autoria de Durkheim: La Division du Travail Social (1893), dois artigos de 1894 depois republicados como capítulos da obra Les Règles de la Méthode Sociologique (1895), dois outros artigos publicados sob o título "Crime et santé social" (1895) e "Lo stato attuale degli studi sociologice in Francia" (1895), a obra Le suicide (1897), o artigo "La Sociologie en France au XIX siècle" (1900) e uma carta ao diretor da Revue Philosophique (1901). Da autoria de Tarde: os artigos "Questions sociales" (1893) e "Les délits impoursuivis" (1894), republicados em Essais et mélanges sociologiques (1895), o Prefácio à La logique sociale (1895), o artigo "La sociologie élémentaire" (1895), fruto de uma palestra feita no I Congrès International de Sociologie, em 1894, republicado sob o título "Les deux éléments de la sociologie" na obra Études de Psychologie Sociale (1898) e os artigos "La criminalité professionnelle" (1896) e "Criminalité et santé sociale" (1895), também republicados nesta obra, o artigo "Les réalités sociales" (1901) e uma menção na obra Les lois sociales (1898). O debate entre Durkheim e Tarde realizado na École des Hautes Études Sociales foi publicado em "La Sociologie et les sciences sociales". Revue Internationale de Sociologie (1904). Cf. BORLANDI, op. cit, 1994. 
debate se deu por meio de um conjunto de textos muito mais amplo, uma vez que há menções indiretas às teorias recíprocas em várias outras publicações não mencionadas por Borlandi ${ }^{5}$. Pode-se mesmo dizer que, entre 1893 e 1904, ou seja, em mais ou menos uma década de publicação, tais autores se referiram um ao outro direta ou indiretamente em quase todos os textos que publicaram. Isso é compreensível quando se considera que as questões debatidas e as posições teóricas assumidas por ambos eram partilhadas por outros círculos intelectuais e que ao fazer a crítica em abstrato ou a um terceiro mantinha-se o debate em surdina sem se expor abertamente aos contra-ataques do adversário. Nesse sentido, o presente artigo incorpora ao debate não apenas os artigos que fazem referência nominal, mas também os que fazem referências implícitas aos dois autores.

É preciso entender que por trás desse debate havia duas posições intelectuais concorrentes e portadoras de recursos sociais e intelectuais muito desiguais. Se Tarde estava em desvantagem em relação ao credenciamento acadêmico, levava a melhor do ponto de vista de suas relações com os meios políticos e intelectuais não universitários. Nesse sentido, é significativo o fato de Durkheim ter começado o debate, uma vez que suas pretensões a uma carreira parisiense estavam sendo ameaçadas pela ascensão de Tarde em Paris ao longo dos anos 1890; atacá-lo seria um meio de criticar posições afins defendidas por grupos que ainda influenciavam as nomeações no ensino superior ou em instituições de prestígio intelectual. Desse modo, pode-se dizer que Durkheim mirava um conjunto muito mais amplo de autores, disciplinas e poderes intelectuais que era preciso combater para que sua própria concepção de ciência social pudesse se legitimar. Tarde, por sua vez, tinha todo interesse em manter tal debate, uma vez que não apenas se projetava no campo intelectual parisiense como alguém à altura de um professor universitário - a quem chamava com ironia de "eminente professor" -, como também conquistava a simpatia daqueles que, mesmo sem grande afinidade com sua teoria, a ele se aliavam contra os ataques de Durkheim e dos colaboradores de L'Année Sociologique.

5 A própria compilação feita por Borlandi é problemática, uma vez que de sua lista constam textos de Tarde em que não há menção explícita a Durkheim, tal como o artigo "La criminalité professionelle", enquanto outros em que essa referência é explícita não foram compilados, como é o caso do artigo "Sympathie et synthèse", publicado na Revue Française d'Édimbourg, em 1897, e republicado em Études de Psychologie Sociale em 1898. 


\section{Divisão do trabalho versus comunidade moral}

A história começa, ao que tudo indica, com as críticas de Durkheim a Tarde na obra De la division du travail social, como atesta Philippe Besnard $^{6}$. Trata-se da tese de doutorado de Durkheim, defendida em 1893, e que contém várias críticas a autores então clássicos da sociologia, tais como Herbert Spencer e Auguste Comte, e a outros em via de legitimação, tais como Tarde, que publicara uma de suas principais obras, Les lois de l'imitation, em 1890. Durkheim faz por volta de dez menções a Tarde ao longo da obra, todas elas caracterizadas por um acordo ou desacordo pontual explicitado em poucas linhas. A obra mais citada é Les lois de l'imitation e, em seguida, La criminalité comparée?.

As discordâncias de Durkheim em relação a Tarde dizem respeito à concepção de evolução de Tarde, que Durkheim cita: “À medida que as aglomerações humanas se estendem, afirma Tarde, a difusão das ideias segundo uma progressão geométrica regular é mais acentuada" ênfase de Tarde nas similitudes sociais ou ideológicas nas sociedades modernas, Durkheim afirma que a civilização é acompanhada por uma maior diferenciação de funções sociais como resultado do aumento do volume e da densidade populacional. Isso significa que, se as sociedades tendem a se assemelhar, os indivíduos tendem a se diferenciar em razão da divisão do trabalho, ou seja, a especialização profissional e a individualização caminham juntas. Segundo Durkheim, “[...] quanto mais recuamos na história, maior é a homogeneidade; por outro lado, quanto mais nos aproximamos dos tipos sociais mais elevados, mais se desenvolve a divisão do trabalho". Ao enfatizar o papel da divisão social do trabalho nas sociedades

6 Steven Lukes, antes de Philippe Besnard, havia atribuído os primeiros ataques a Tarde em razão do artigo “Questions sociales”. LUKES, S. op.cit., p. 303. Cf. BESNARD, P., op. cit., 1995 ou 2003.

7 Ao contrário do que afirma Borlandi, que tende a enfatizar o ar respeitoso de Tarde em detrimento do espírito áspero de Durkheim, parece-me que tanto Durkheim quanto Tarde elogiaram a obra um do outro nos pontos que consideravam louváveis. No caso da obra Da Divisão do Trabalho Social, Durkheim concorda com Tarde em mais de um tópico. Concorda, por exemplo, com o menor envolvimento das mulheres do que o dos homens na civilização, o que sugere certos traços típicos das naturezas primitivas, bem como com o caráter profissional das diferentes sociedades do crime e do delito. Da Divisão do Trabalho Social. São Paulo, Martins Fontes, 1999, p. 241 e p. 323. As referências na edição brasileira visam facilitar o acesso ao leitor local; é o caso também das Regras do Método Sociológico e d'O Suicídio.

8 DURKHEIM, É. Da Divisão do Trabalho Social. São Paulo: Martins Fontes, 1999, p. 114.

9 Idem, ibidem, p. 115. 
modernas, Durkheim dá menor peso às homogeneidades características dos Estados ou culturas nacionais ${ }^{10}$. Além disso, afirma que a atração pelo diferente/complementar é mais forte do que pelo semelhante, de modo que a coesão social nas sociedades com divisão do trabalho é maior do que nas sociedades tradicionais ou segmentares. No prefácio à segunda edição da obra De la division du travail social, de 1902, reafirma a importância dos grupos profissionais e das novas corporações para a solidariedade social nas sociedades modernas. A divisão do trabalho e as associações profissionais não seriam apenas, portanto, fatos sociais, mas também teriam um papel fundamental na produção da harmonia social.

A divisão do trabalho intelectual também foi objeto das reflexões de Durkheim por meio da oposição entre as noções de "diletante" e de "especialista". Durkheim critica o "diletante", tachando-o de "superficial" ou portador de uma "falsa profundidade", além de inconstante e incapaz de formular uma obra verdadeiramente pessoal ${ }^{11}$. Se, para Durkheim, a especialização profissional não é um fenômeno atentatório à individualização, isso também se aplica ao mundo intelectual: "o diletante é quem conserva intacta sua simplicidade primitiva. A complexidade de sua natureza é apenas aparente. [...] O diletante atenuou e afinou as potências de seu ser, mas não soube transformá-las e remanejá-las para extrair delas uma obra nova e definida; nada ergueu de pessoal e de duradouro no terreno que a natureza lhe legou"12.

Ora, Tarde se opôs frontalmente a Durkheim no que diz respeito a todas essas questões. Num artigo fundamental denominado "Questions sociales", de 1893, uma resenha crítica de três obras de sociologia ${ }^{13}$, entre

10 Nas sociedades políticas, afirma Durkheim, a diferença que se verifica entre as regiões ou províncias abarca um conjunto de indivíduos mais semelhantes entre si, enquanto numa sociedade mais uniformizada politicamente existe uma quantidade muito maior de tipos individuais. Se, portanto, a civilização nivela os "tipos coletivos", ela exerce efeito contrário sobre os "tipos individuais". Da Divisão do Trabalho Social, p. 115-116.

11 DURKHEIM, É. Da Divisão do Trabalho Social, Livro II, cap. IV e V, p. 318, 328 e 348.

12 Idem, ibidem, Livro II, cap. IV, p. 318.

13 Além da obra de Durkheim, são resenhadas La lutte des races, de Ludwig Gumplowicz, e La lutte entre les sociétés, de Jacques Novicow. TARDE, G. "Questions sociales". Revue philosophique, 1893, p. 618-638. Esse artigo foi republicado em Essais et mélanges sociologiques. Paris: A. Maloine, 1895. Disponível no site Classiques des Sciences Sociales (http://classiques.uqac.ca) e na biblioteca virtual da Bibliothèque Nationale de France (http://gallica.bnf.fr/). Vários artigos e obras aqui tratados podem ser encontrados nesses dois domínios da internet. 
as quais De la division du travail social, Tarde responde às críticas de Durkheim ${ }^{14}$. Em relação à divisão do trabalho, critica o papel que Durkheim lhe dá na produção da solidariedade social, uma vez que para ele a solidariedade se constitui por meio da comunhão de ideias e de sentimentos e não através de interesses de grupos profissionais. Tarde é bastante explícito a esse respeito:

Manifestamente, a divisão do trabalho não é nem socializante nem moralizante lá onde, levada ao limite, ao ponto de apagar toda comunhão de ideias, de costumes, mesmo de língua entre as classes profissionais, ela as acentua em castas, profundamente divididas. [...] Com efeito, a oposição estabelecida pelo Sr. Durkheim entre as duas espécies de solidariedade social que ele admite, em que uma se substitui necessariamente à outra, parece-me ilusória ${ }^{15}$.

Se, por um lado, Tarde aceita a tese da "solidariedade mecânica" de Durkheim à medida que a interpreta como parte de sua teoria das semelhanças por imitação, por outro lado, é inegável o intuito de Tarde de identificar a "solidariedade orgânica" de Durkheim ao organicismo, ao utilitarismo ou ao materialismo econômico. A importância dada por Durkheim à divisão do trabalho, fenômeno segundo Tarde essencialmente econômico ou de ordem material, não poderia definir aquilo que é de natureza social e que seria da ordem do "mental"; uma instituição que opera sob a lógica da oposição material entre grupos e indivíduos não poderia ser capaz de contribuir para a solidariedade social.

14 Na obra Da Divisão do Trabalho Social não há nada equivalente ao tom de Tarde: "O Sr. Durkheim, um hesitante excessivo, pensador circunspecto, aplicado, tenaz, penetrante não por brechas nem balanços bruscos, mas pela união amorosa e sucessiva com seu objeto, com facilidade imagina externamente o desenvolvimento fecundo e pacífico que sente em si mesmo." TARDE, Gabriel, "Questions sociales". Revue Philosophique, p. 622, 1893. Ou ainda, numa versão mais irônica, dois anos depois: "O Sr. Durkheim, sonhador tenaz e tranquilamente excessivo, lógico imperturbável, mais profundo do que justo, capcioso ao ponto de abusar e de demonstrar que suas construções a priori são verdades de observação, com facilidade imagina externamente a continuidade de desenvolvimento lógico e de desenvolvimento pacífico que ele sente em si mesmo." TARDE, G. "Questions sociales". Essais et mélanges sociologiques, op. cit., site Les Classiques des Sciences Sociales, p. 137.

15 Cf. TARDE, G. “Questions sociales”. Essais et mélanges sociologiques, p. 145-146. 
Segundo Tarde, a moralização dos indivíduos tem sua fonte na sociabilidade, processo psicológico que se dá por meio do contágio imitativo - mas também pela simpatia inata dos indivíduos - e tem como corolário o fortalecimento de crenças e costumes semelhantes nos grupos sociais tradicionais e nas nações modernas. Tal identidade seria ao mesmo tempo a resultante e um fator de solidariedade social. Não existem, portanto, duas formas distintas de solidariedade, pois ambas se baseiam na semelhança e na comunhão de crenças e de desejos ${ }^{16}$. Enquanto Durkheim procurava, com sua tese, conceber as sociedades modernas para além do materialismo e do cálculo utilitarista, mas sem cair no idealismo, é nessa última direção que se encaminha Tarde; ao contrário de funções e órgãos, são as ideias e os bons exemplos que moralizam os homens. Com o aumento de sua circulação nas sociedades modernas em função dos progressos da imprensa, da educação e das vias de comunicação em geral, Tarde admite que elas tenderiam a uma maior moralidade do que as sociedades tradicionais. A maior intensidade e exposição às ideias promoveria, por um lado, maior individualidade e, por outro lado, maior difusão de algumas poucas ideias no seio de vários grupos sociais em razão de sua força de difusão.

Para enfatizar a importância da dimensão "mental" em detrimento da "material", Tarde utiliza a oposição entre o "luxo" e o "trabalho", mas também entre o "artista" e o "cientista". Contra a importância do trabalho útil e a observação do cientista, ele defende a sensibilidade estética do "artista" e a importância do "inútil" nas sociedades modernas. A socialização e a individualização são processos que não podem ocorrer por meio do trabalho, mas sim do "tempo livre", o que deverá ocorrer com a diminuição gradual da jornada de trabalho nas sociedades modernas ${ }^{17}$.

Apesar de admitir o aumento da moralidade nas sociedades modernas, Tarde tem dificuldade em conciliar seu conceito de evolução social com os processos sociais que observa, tanto no plano material quanto no moral. Isso porque as "crenças" e "desejos" dos diversos grupos sociais também representam uma ameaça de nivelamento diante da riqueza moral e

16 "Toda sociedade é constituída sobre esse tipo [segmentário]. Unicamente, ocorre que os segmentos similares aumentam: em princípio, o clã ou a tribo; nos nossos dias, a nação.” TARDE, "Questions sociales". Essais et mélanges sociologiques, p. 143.

17 Idem, ibidem, p. 149-150. 
intelectual dos indivíduos da elite, de cuja preservação depende o progresso social ${ }^{18}$. Sua "psicologia das multidões" é emblemática dessa tensão, uma vez que os processos de moralização coletiva são sempre acompanhados por uma regressão no plano intelectual. Assim, numa conferência em Bordeaux, em 1901, ele afirma: "sei bem que a substituição do trabalho manual ou, melhor, da produção pessoal em todo tipo de função, industriais, militares e até mesmo científicas pelo trabalho industrial, pela produção impessoal e coletiva é a característica da nossa era. [...] Mas há razões para se pensar que essa é uma fase transitória, uma era mediana a atravessar até alcançar uma era renovada em que o valor individual retomará seu lugar, o primeiro" 19 (grifo meu). Percebe-se certa nostalgia no pensamento de Tarde, expressa pela oposição, típica entre os filósofos do período, entre a "civilização anglo-saxônica" e a "cultura francesa", esta supostamente vocacionada às tarefas do espírito e à criação estética.

Como não poderia deixar de ser, a discussão mais geral sobre a divisão do trabalho se refletiu também nas representações sobre o intelectual e sobre a divisão do trabalho intelectual nas sociedades modernas. Se Durkheim havia criticado o "diletante", Tarde critica o trabalho "impessoal" e "coletivo", ou seja, as práticas intelectuais inauguradas por Durkheim e o círculo intelectual universitário em torno da revista L'Année Sociologique. Desse modo, enquanto Durkheim se distinguia do juiz tachando-o de diletante ou praticante das ciências sociais nas horas vagas, Tarde se diferenciava do professor universitário porque ele representaria a própria "proletarização do intelectual" que ele tanto temia. Para Tarde, o regime de "meditação solitária", típico do homem de letras voltado ao cultivo do espírito, devia ser o modelo do intelectual moderno.

18 “Assim, não é o número de indivíduos, mas de ideias novas, de exemplos civilizadores lançados na circulação geral que faz a grandeza dos povos. O essencial é conservar, desenvolver as qualidades individuais que nos distinguem e, democratizando-nos, permanecer uma nação aristocrática [...]". Sur la pretendue décadence des peuples latins, conferência feita no Atheneu de Bordeaux em 21 de maio de 1901, p. 24.

19 Idem, ibidem, p. 20. 


\section{Romantismo versus positivismo cientifico}

No artigo "Questions sociales", de 1893, Tarde inaugura outro ponto de divergência importante em relação a Durkheim e que diz respeito à concepção de ciência e de evolução social. Ao opor a noção de "acaso" à de "regularidade", enfatiza a importância do imprevisto na história e considera a regularidade uma dimensão redutora da realidade. Em relação ao olhar de Durkheim sobre o curso da história, Tarde afirma: "Ele não atribui nenhum papel ao acidental, ao irracional, essa fase dissimulada do fundo das coisas; nem mesmo ao acidente do gênio, que é um desses primeiros começos dos quais fala Renouvier [...]"20. No texto "La Sociologie", publicado na obra Études de Psychologie Sociale, de 1898, Tarde volta a enfatizar o papel do "acaso" na evolução social. Escrito claramente contra Durkheim, apesar de não citá-lo, Tarde pretende mostrar as insuficiências do "método" e da percepção da "regularidade" diante da singularidade individual e histórica. Ou seja, trata-se de mostrar a incapacidade da ciência de dar conta da totalidade do real e principalmente de seus aspectos mais importantes. A oposição entre indivíduo/individualidade e sociedade/coletividade alcança expressão máxima na sua teoria da invenção (ou da originalidade individual). Isso porque para Tarde os verdadeiros "atores da história" são os indivíduos e não fatores impessoais ou coletivos. Admitir, como quer Durkheim, que as "criações" são produtos do seu tempo implicaria “[...] negar o gênio, a criatividade e a invenção como atributos dos 'grandes homens' - e mesmo dos homens comuns". Pois toda mudança social se deve ao papel do indivíduo na história, responsável por inaugurar uma nova ideia ou comportamento, ou melhor, uma nova crença ou desejo para além das determinações sociais. Os fatores coletivos e impessoais, tais como "inconsciente", "multidão" e "meio social", se opõem a termos tais como "gênio", "consciência", "invenção", "originalidade", "diferença", fenômenos indetermináveis pela sociologia e, a bem da verdade, por qualquer ciência, uma vez que são frutos do "acaso biológico e psicológico"21. Um homem de gênio não pode ser a simples resultante das aspirações ou necessidades de um povo e muito menos é

20 TARDE, G. "Questions sociales”. Éssais et mélanges sociologiques, op. cit., p. 141.

21 TARDE, G. "La Sociologie". Études de Psychologie Sociale, p. 33-37. 
alguém que vem "na sua hora". As verdadeiras criações são individuais e extrassociais e não podem ser frutos de qualquer necessidade social, pois criam as necessidades que querem atender.

Apesar de Tarde pretender, por um lado, elaborar uma teoria social científica e defender o valor da ciência contra o misticismo, por outro lado, o escopo dos fenômenos sociais passíveis de explicação científica torna-se desse modo restrito, pois cede grande espaço àqueles que a razão não alcança porque são imprevisíveis, casuais ou irracionais. Mais importante ainda é o fato de Tarde dar maior valor àquilo que a ciência não alcança do que ao que ela pode determinar. Assim, a ciência e a razão acabam por ter uma posição dominada ou um valor menor no seu pensamento diante da arte e da sensibilidade. No artigo "Questions sociales", Tarde pergunta: "Quem tem razão?", numa espécie de tradução do seu debate com Durkheim a partir da oposição "ciência versus arte". E ele mesmo responde: "o artista tem razão e o cientista está errado" 22 . A instantaneidade das visões do artista, a "síntese original", vale mais do que as contemplações de objetos duráveis pelo cientista, que ele considera uma "repetição banal".

De maneira correlata, Tarde também valoriza o que há de "pessoal" ou "singular" no próprio processo cognitivo, tornando constitutiva e essencial ao conhecimento a atitude moral e afetiva do pesquisador em relação ao seu objeto. No artigo "Les deux élements de la Sociologie", de 1894, numa clara crítica ao racionalismo durkheimiano, ele enfatiza a sensibilidade e o temperamento do pesquisador, bem como o vínculo afetivo com o objeto de estudo ${ }^{23}$. No artigo "Criminalité et santé sociale", de 1895, relativiza o papel da ciência: ela não pode dirigir o desejo e, se tem autoridade sobre o pensamento, não possui autoridade sobre a consciência e o coração. Caso se dê à ciência um papel muito grande, como quer Durkheim, abre-se o

22 Idem. "Questions sociales". Essais et mélanges sociologiques, p. 148-149.

23 "A primeira condição para ser naturalista é amar a vida, fraternizar com todos os seres vivos, sentir o que há de bondade escondida nos mais terríveis [gestos ou indivíduos]. [...] a primeira condição para ser sociólogo é amar a vida social, simpatizar com os homens de todas as raças e de todos os países reunidos em torno de um centro, pesquisar com curiosidade, descobrir com felicidade o que há de devoção afetuosa na luta do selvagem considerado o mais feroz, às vezes até mesmo resguardá-lo do malfeitor, enfim, nunca crer facilmente na estupidez, na maldade absoluta do homem em seu passado, nem a sua perversidade presente, e nunca se desesperar de seu devir." TARDE, Gabriel. "Les deux éléments de la Sociologie". Écrits de Psychologie Sociale, p. 94. 
flanco para que se decrete sua bancarrota ${ }^{24}$. Ao republicar o mesmo artigo, em 1898, inclui um apêndice com uma resposta ainda mais contundente a Durkheim, afirmando que este despreza o "coração, o amor, a simpatia, a imaginação, fonte de hipóteses e de teoria, assim como de poesia e arte". E conclui: Durkheim é um antimístico e um positivista ${ }^{25}$.

Não é difícil ver nos trechos acima uma réplica de Tarde à seguinte frase de Durkheim em Les Règles de la méthode sociologique ${ }^{26}$ : "Uma ciência feita assim só pode satisfazer os espíritos que gostam de pensar com sua sensibilidade e não com seu entendimento, que preferem as sínteses imediatas e confusas da sensação às análises pacientes e luminosas da razão. O sentimento é objeto de ciência, não o critério da verdade científica" ${ }^{27}$. Contudo, aquelas palavras de Tarde foram dirigidas principalmente ao artigo "Crime et santé sociale" de Durkheim que, por sua vez, havia sido publicado como resposta ao artigo "Criminalité et santé sociale" de Tarde, ambos de 1895. Ao final de seu artigo, Durkheim subira o tom e afirmara que a diferença entre ele e Tarde seria mais profunda e viria do fato de que ele, ao contrário de Tarde, acreditava na ciência e em sua função reguladora da conduta, enquanto Tarde lhe atribuiria um papel menor e de pouca serventia social. Pois Tarde "coloca acima da razão a sensação, o instinto e a paixão, todos elementos inferiores e obscuros de nós mesmos" ${ }^{28}$. Do ponto de vista teórico, ele seria um místico e o misticismo é o reino da fantasia intelectual e da anarquia na vida prática ${ }^{29}$.

24 Nesse momento, havia um debate entre os partidários da ciência e os defensores da religião, tais como Ferdinand Brunetière, que decretou a "bancarrota" ou a "falência" da ciência. Cf. BRUNETIÈRE, F. "Après une visite au Vatican". Revue des Deux Mondes, 1895 e "La banqueroute de la science". Figaro, 1895. Cf. LALOUETTE, J. "La querele de la foi et de la science et le banquet Berthelot". Revue Historique, n. 608, p. 825-844, 1998 e HARRY, Paul. "The Debate over the Bankruptcy of Science in 1895". French Historical Studies, v. 5, n. 3, 1968, p. 299-327.

25 TARDE, Gabriel. "Criminalité et santé sociale". Études de Psychologie Sociale, op. cit., p. 160 .

26 A obra foi publicada originalmente em 1894, na Revue Philosophique, sob o título "Les règles de la méthode sociologique". Cf. Durkheim, Émile, Revue philosophique, 1894/1, p. $465-498$ e p. 577-607, e 1894/2, p. 14-39 e p. 168-182.

27 DURKHEIM, É. As Regras do Método Sociológico. 3. ed. São Paulo: Martins Fontes, 2007, p. 34-35.

28 DURKHEIM, É. "Crime et santé sociale”, site Les Classiques des Sciences Sociales, p. 9. Publicado em KARADY, Victor (Org.). Durkheim Textes, 2, p. 173-180. Originalmente publicado na Revue Philosophique, v. 39, 1895, p. 518-523.

29 Idem, ibidem. 
Ora, esse é o ponto em que os dois autores mais se diferenciaram, uma vez que a atitude racionalista e o método sociológico de Durkheim pressupõem o distanciamento do cientista em relação ao seu objeto. A disciplina profissional vem da prática no método, mas também da habilidade de ignorar as respostas mais simpáticas ou imediatas à própria consciência. Nada mais distante de seu método do que estabelecer uma relação simpática ou intuitiva com o objeto de estudo, como quer Tarde. Além disso, a aposta de Durkheim na enorme capacidade da ciência em explicar e conduzir a vida social se choca com o papel menor e subordinado que lhe caberia segundo Tarde. Enquanto Durkheim espera que a ciência dê respostas sobre o que é "normal" e "patológico" ao ponto de orientar os desejos na direção correta, para Tarde ela, por si só, sem um "impulso instintivo e apaixonado", jamais poderia suscitar no indivíduo o sacrifício de si em nome da sociedade.

Num artigo para uma revista italiana chamado "L'état actuel des études sociologiques en France", também de 1895, Durkheim volta ao tema do acaso na história e do valor social da ciência. A sociologia de Tarde representa "a negação da ciência"; ela coloca o "irracional e o milagre" na base da vida e, em consequência, da ciência social, pois todas as instituições coletivas seriam frutos da generalização de uma descoberta, de uma invenção que se fez não se sabe como e que são produto de um puro acidente. A própria evolução seria concebida como fruto de bizarrices, curiosidades e imprevistos segundo o acaso. Se não há sentido algum na evolução social, nenhuma regularidade, nenhuma uniformidade, a própria teoria da imitação de Tarde estaria em xeque. Com o acaso, abre-se a porta à imaginação, pois aquilo que é casual se presta a qualquer tipo de "prova" 30 .

Desse modo, conclui-se que a obra de ambos os autores representa duas atitudes opostas diante da ciência social e, mais do que isso, duas tomadas de posição em relação ao conhecimento em geral: uma atitude romântica, no caso de Tarde, e uma atitude racionalista, no caso de Durkheim.

30 DURKHEIM, É. "L'état actuel des études sociologiques en France", site Les Classiques des Sciences Sociales, p. 16-17. Originalmente publicado sob o título "Lo stato attuale degli studi sociologici in Francia", na revista italiana La Reforma Sociale, v. 3, n. 2, p. 607-622. 


\section{Sociologia versus Psicologia}

Desde a obra De la division du travail social, a discussão sobre o conceito de fato social e sobre a causalidade em ciências sociais havia se tornado objeto de divergência entre os dois autores e a questão perdurou ao longo de toda a década. Os modelos de explicação dos fenômenos sociais tenderam a se diferenciar segundo a opção por causas específicas e sociológicas (Durkheim) ou gerais e psicológicas (Tarde). Em De la division du travail social, Durkheim afirmara que "uma simples lei da imitação" não poderia explicar a diminuição das diversidades locais (costumes, religiões, organização familiar) ou a uniformização social em sociedades nacionais ${ }^{31}$. A imitação também não poderia explicar o nivelamento entre as classes sociais, pois para que as classes inferiores ambicionem a vida das classes superiores é preciso que "as diferenças que separavam primitivamente essas classes tenham desaparecido ou diminuído", dando origem a novas aptidões e gostos em desequilíbrio com as antigas funções. Desse modo, "a imitação nada pode explicar por si só, pois supõe outra coisa que ela mesma" ${ }^{32}$. No texto "Les Règles de la méthode sociologique", ele critica explicitamente a teoria psicológica de Tarde: “[...] nossas pesquisas não nos fizeram constatar em parte alguma essa influência preponderante que o $\mathrm{Sr}$. Tarde atribui à imitação na gênese dos fatos coletivos. [...] Não apenas a imitação nem sempre exprime, mas inclusive nunca exprime o que há de essencial e característico no fato social" ${ }^{\prime 3}$.

Ao criticar a teoria psicológica de Tarde, Durkheim pretende autonomizar a sociologia da psicologia ${ }^{34}$ admitindo uma dimensão da realidade exclusivamente social, ou seja, não redutível aos fenômenos biológicos ou psicológicos. Por oposição aos fenômenos psíquicos, que "só têm existência na consciência individual e através dela", os fenômenos sociológicos têm por substrato a sociedade. Isso significa que as ideias chegam aos indivíduos de fora e não são, como pensa Tarde, criadas por eles e assimiladas por imitação. Se o fato social é exterior à consciência dos indivíduos, pois são 
práticas e crenças coletivas complexas, podem ser identificados por uma característica particular: exercem uma força coercitiva sobre os indivíduos mesmo que estes não a percebam como tal.

No artigo "L'état actuel des études sociologiques en France", de 1895, ele volta a criticar a teoria da imitação e nega sua importância teórica com base em quatro argumentos principais: 1) jamais se deu uma prova direta e indutiva da ação da imitação, demonstração, aliás, que ele julga impossível; 2) a imitação não tem um papel importante, uma vez que um fato social pode ser "geral" sem ser fruto da imitação; é geral porque provém de suas "condições de existência" e se impõe aos indivíduos; 3) um ato de pura imitação ou "expansão puramente automática" não se difunde sem predisposição social preexistente e 4) o contágio imitativo deve ser, provavelmente, uma forma excepcional ou anormal do desenvolvimento histórico ${ }^{35}$.

As críticas à teoria da imitação de Tarde se intensificaram em 1897 com a publicação de Le Suicide, conforme apontou Philippe Besnard, uma vez que todo o capítulo quarto do Livro I é dedicado a criticar essa teoria. Ao analisar o debate, Besnard afirma que Durkheim cometeu vários equívocos na interpretação que fez da teoria da imitação de Tarde, pois teria reduzido a dimensão consciente e ativa do sujeito da imitação a uma ação puramente reflexa, instintiva e passiva ${ }^{36}$. De fato, Durkheim simplificou enormemente a teoria de Tarde para desqualificar sua explicação psicológica, muito embora tal leitura fosse comum entre os críticos de Tarde, uma vez que em seus estudos sobre as "multidões" ele próprio havia enfatizado o aspecto instintivo ou inconsciente da imitação por contágio ${ }^{37}$.

Em Le Suicide, Durkheim afirma que o termo "imitação" é utilizado em três sentidos muito distintos, o que geraria toda sorte de equívocos. É

35 DURKHEIM, É. "L'état actuel des études sociologiques en France", publicado originalmente em italiano. Durkheim, Émile, La reforma sociale, 2, v. 3. "Lo stato attuale degli studi sociologici in Francia", p. 607-622 e p. 691 a 707. Encontra-se a versão francesa, publicada em KARADY, Victor. Textes, 1, Paris: Minuit, 1975 no site Les Classiques des Sciences Sociales, p. 1-28.

36 BESNARD, P. "Durkheim critique de Tarde: des Règles au Suicide", op. cit., p. 76-77, 2003.

37 Aliás, veremos que o mesmo equívoco ocorreu em relação a Durkheim, particularmente com a interpretação do fato social como "coisa" e como algo "exterior" aos indivíduos. Sobre a psicologia das multidões de Tarde, consultar TARDE, Gabriel. A opinião e as massas. São Paulo: Martins Fontes, 1992. 
preciso lembrar que ele está pensando nas causas do suicídio coletivo, ou seja, nas taxas mais ou menos constantes de suicídios e em outros tipos de "correntes sociais". Em primeiro lugar, ele recusa que o termo "imitação" possa ser usado para caracterizar "a propriedade que têm os estados de consciência experimentados simultaneamente por um certo número de pessoas de agir uns sobre os outros e de se combinar dando origem a um estado novo"38. Em relação a esse estado social, típico da "multidão", Durkheim afirma que ou se trata, em seu início, de simples impressão sensível tal como a que os corpos exteriores exercem sobre nós ou, quando no estado propriamente coletivo, de fusão ou criação de algo novo, ou seja, de um processo de criação coletiva e não de "modelos ou cópias". Durkheim aceitaria o termo "imitação" para caracterizar ou explicar tal fenômeno desde que se provasse que toda multidão se inspira num mentor ou líder, mas ele mesmo afirma que isso não está provado. Em segundo lugar, o autor recusa o termo imitação para caracterizar a "necessidade que nos impele a nos colocarmos em harmonia com a sociedade e, com essa finalidade, a adotarmos maneiras de pensar ou de fazer que são gerais à nossa volta" ${ }^{" 39}$. Nesse caso, afirma Durkheim, ao menos há alguma reprodução de práticas alheias. No entanto, afirma que não se as reproduz por um "instinto de imitação", como quer Tarde, mas sim por uma espécie de "simpatia" com os de nossa convivência, bem como pela pressão da coletividade sobre cada indivíduo para "prevenir dissidências e nutrir o sentimento de respeito". E conclui: "agir por respeito ou por receio da opinião não é agir por imitação"40. Há, portanto, uma tentativa de Durkheim de identificar uma causalidade exterior - fruto de um "estado geral do meio social" - nas relações pessoais ou interpessoais. Mesmo admitindo a ação da imitação por contágio ${ }^{41}$, trata-se de buscar outras razões para reproduzir um ato ou ideia dado que não se pode provar a priori que seus efeitos, "individuais e esporádicos", tenham consequências sociais. Além disso, se caracterizarmos como imitativo tudo

38 DURKHEIM, É. O suicídio. São Paulo: Martins Fontes, 2000, p. 131.

39 Idem, ibidem, p. 131.

40 Idem, ibidem, p. 136.

41 Sobre a explicação do suicídio pelo contágio, conferir O Suicídio, op. cit., p. 140-143, em que ele afirma que os suicídios imputáveis à imitação são numerosos. Durkheim também admite a ação do contágio no fenômeno das greves trabalhistas. Cf. Da Divisão do Trabalho Social, Livro I, Cap. VI, p. 213 e Livro II, Cap. 3, nota. 31. 
o que não for uma estrita invenção individual, tudo seria fruto da imitação e ela nada teria de específico.

A única modalidade de fenômeno para a qual Durkheim aceita a qualificação de "imitação" seria a pura reprodução de um modelo de comportamento exterior com a exclusão de qualquer outra razão a não ser a exposição ao mesmo, como ocorre com ações reflexas tais como "chorar, rir, bocejar" ${ }^{42}$. Do ponto de vista social, esse processo supõe a contiguidade geográfica entre populações ou o acesso via imprensa aos centros mais visíveis e prestigiosos (capitais e grandes cidades), que serviriam de modelo e seriam mais facilmente imitáveis. Com base em mapas estatísticos do suicídio, Durkheim recusa a teoria de que haveria centros de imitação que se irradiam ou se propagam para a periferia. Não é a imitação, mas condições de existência análogas (o meio social) que explicariam taxas semelhantes de suicídios. A conclusão do capítulo soa como uma crítica implícita à sociologia de Tarde, aquela que se "furta às obrigações regulares da prova", que é fruto da "dogmatização" e não passa de uma proposição apoiada em "considerações vagamente metafísicas"

Tarde responde às primeiras críticas de Durkheim por meio de vários artigos ${ }^{44}$. Em primeiro lugar, a defesa da psicologia e da teoria da imitação exige a crítica do conceito durkheimiano de fato social. As críticas podem ser sintetizadas pelos seguintes tópicos: 1) uma "coisa social" qualquer se transmite não do grupo ao indivíduo, mas de um indivíduo ao outro, ou seja, os fatos sociais são interiores e não exteriores e se difundem através das consciências individuais; 2) uma "coisa social" tem origem num indivíduo inovador, eminente ou desconhecido; não pode haver progresso se na origem das sociedades os homens têm a mesma inteligência medíocre, mas apenas quando algum deles é superior ${ }^{45}$; 3 ) não existe uma

42 "Há imitação quando um ato tem como antecedente imediato a representação de um ato semelhante, anteriormente realizado por outros, sem que entre essa representação e a execução se intercale nenhuma operação intelectual [...]". DURKHEIM, É. O Suicídio, p. 138.

43 DURKHEIM, É. O Suicidio, op. cit., p. 162.

44 Principalmente através dos seguintes artigos: "Les deux élements de la Sociologie", "Les délits imporsuivis" e "Criminalité et santé sociale". Cf. Nota 5.

45 "Ideias de gênio, concebidas por um cérebro e propagadas em seguida em muitos outros - o que supõe, de um lado, boas fortunas bem raras, acidentais ou inseminadas, do gênio ou engenhosidade e, de outro lado, a docilidade imitativa da mediocridade: eis, se não abuso, ao que se reduz o mistério histórico". TARDE, G. "Les deux éléments de la Sociologie", op. cit., p. 77. 
sociedade sui generis acima dos indivíduos; essa é uma expressão abstrata da realidade e uma verdadeira "ontologia escolástica"; 4) a "coerção" seria um fenômeno que se impõe por meio da força e que tenderia a ter menos importância quanto mais civilizada a sociedade; no caso das "multidões", divididas em líderes e liderados, não se pode aplicar o termo coerção aos primeiros, mas apenas aos segundos e 5) a imitação se dá por meio de um processo "simpático" entre os indivíduos e não por imposição $0^{46}$.

No artigo "Les deux éléments de la Sociologie", de 1894, Tarde advoga a autonomia da sociologia em relação à biologia, mas defende sua subordinação à psicologia: "o caráter distintivo de um pensamento, de uma vontade, de uma ação social é o fato de ser feito à imagem e semelhança dos pensamentos, vontades e ações dos outros" ${ }^{\prime 4}$. Como poderia um fato social existir fora das consciências individuais como quer Durkheim? Não é de fora para dentro, do grupo tomado coletivamente sobre o indivíduo que se transmitem os fatos sociais, mas sim de um indivíduo ao outro e, nesse processo, com refração. A partir de uma inovação produzida por um indivíduo, ilustre ou anônimo, forma-se por meio da imitação e da refração um conjunto que é toda a realidade social num determinado momento. Os termos para caracterizar a teoria de Durkheim são duros: "ontologia escolástica", "teoria da emanação" e "platonismo". Além disso, não se deve tentar manter a sociologia isolada das demais ciências, uma vez que os fatos sociais também estão ligados à constituição mental e vital do ator (fatos sociopsíquicos), bem como ao meio físico (fatos sociofísicos). No que diz respeito ao caráter "coercitivo" do fato social, ele o interpreta como uma teoria do poder e por isso reduz seu alcance aos fatos sociais que envolvem relações de força. Em oposição à "força", enfatiza a "simpatia", ou seja, o apreço ou o amor devotado aos de sua convivência, tanto como fruto da sociabilidade quanto como parte da constituição dos indivíduos. O que é "inato" ou "instintivo" faz parte da explicação sociológica: "no fundo existe a sociabilidade humana, inata na criança a mais refratária. Quando,

46 Nas Lois sociales, Tarde recusa o constrangimento como característica do fato social porque, segundo ele, uma inovação qualquer não pode ocorrer por obrigação, mas sim por "persuasão e sugestão branda". Por trás de todo monumento ou construção intelectual deve residir a capacidade criativa de um indivíduo e ela seria incompatível com a ideia de que um fato social costuma exercer sobre os indivíduos de uma sociedade certo peso. TARDE, G. Lois sociales. Esquisse d'une sociologie. Paris: Alcan, 1898. Cf. site Les Classiques des Sciences Sociales, p. 22, nota 1 e p. 61-64.

47 TARDE, G. "Les deux élements de la Sociologie", op. cit., p. 66. 
por acaso, ela falta numa criança, é inútil corrigi-la, pois sua educação é impossível" ${ }^{48}$. Até mesmo a fundação de um novo Estado tem causas naturais ou espontâneas, seja a "simpatia natural" seja a "tendência à associação", mas não o constrangimento.

Tarde não publicou nenhuma resposta explicitamente dirigida a Durkheim após a publicação de Le Suicide, ainda que tenha preparado um manuscrito para refutá-lo. Não se sabe a razão pela qual Tarde não publicou esse texto, uma vez que ele afirma que essa obra teria sido escrita integralmente como uma refutação à sua teoria ${ }^{49}$. No manuscrito, as principais críticas à teoria de Durkheim podem ser assim sintetizadas: 1) os suicídios podem até ser normais, mas são causados "pelas ideias germinadas nas relações sociais" com os seus semelhantes; 2) toda sociedade tem início pela imitação de um líder ou mestre e uma comunidade moral só pode se estabelecer pela acumulação de exemplos; 3) a imitação ou reprodução da natureza não é idêntica à imitação com o uso da alma, a última apenas reservada às almas mais civilizadas, acostumadas à imitação do semelhante; 4) a imitação tem um peso muito maior na propagação das línguas, das religiões e das artes do que na propagação de suicídios; se ela tem peso maior sobre objetos culturais, sua refutação pelas taxas de suicídio não é decisiva, ou seja, as taxas mostradas por Durkheim não invalidam a influência do suicídio; 5) a imitação pode ser combinada com uma predisposição física ou psíquica: ela é uma mistura do meio social com a hereditariedade; 6) as religiões podem prevenir mais ou menos contra o suicídio, mas as pessoas são religiosas por causa do exemplo dos pais; 7) a imitação pode se combinar com outras causas sociais, mas todas elas têm origem no exemplo; 8) a indulgência no modo como são noticiados os suicídios na imprensa é parte da explicação de sua multiplicação e 9) fatos singulares aumentam as taxas sociais de suicídio. Observa-se nesses argumentos a aplicação da psicologia social tardeana ao fenômeno do suicídio, isto é, a ideia de que as "correntes sociais" resultam fundamentalmente de um movimento que tem

48 Idem, ibidem, p. 72.

49 Borlandi e Besnard sugerem algumas hipóteses para explicar tal silêncio: o pequeno conhecimento de Tarde da estatística e do fenômeno do suicídio, sua preocupação com a indicação para um posto no Collège de France ou simplesmente uma possível insatisfação com a resposta que havia preparado. Cf. BORLANDI, Massimo; BESNARD, Philippe. "Contre Durkheim à Propos de son Suicide", op. cit., p. 219-220. 
origem nas relações interindividuais e cuja expansão depende de processos psicológicos imitativos de um determinado modelo de conduta.

Ainda dois aspectos merecem destaque no manuscrito. Em primeiro lugar, o suicídio de um "homem superior", tal como um militar de alta patente, seria sempre uma decisão consciente e jamais resultado de um processo "inconsciente", ou seja, um ato mecânico e carente de "individualidade" 50 . Certos indivíduos têm, para Tarde, muito mais poder sobre seu próprio destino do que teriam para Durkheim: são capazes de refletir sobre o próprio suicídio e de pesar as vantagens e desvantagens segundo seus interesses. Nesse sentido, um indivíduo "mais independente" ou com "personalidade mais forte" não poderia ter maior propensão ao suicídio, uma vez que não pode ser arrastado por uma imposição social. Em segundo lugar, Tarde realça seu acordo com os historiadores em oposição a Durkheim: este enquadra a evolução em fórmulas e reduz as maiores proezas dos grandes homens a acidentes sem nenhuma importância, enquanto ele, Tarde, não questiona a história nem quer dirigi-la, mas somente esclarecê-la melhor ${ }^{51}$.

A importância fundamental que Tarde atribui às relações interindividuais corresponde à ênfase no conteúdo psicológico ou mental que aí circula - crenças e desejos. As instituições sociais, nesse sentido, são sempre conjuntos de ações que resultam de uma ideia original posteriormente imitada. Ao opor idealismo e materialismo, ou seja, as produções mentais e as necessidades materiais ou institucionais, Tarde pretende preservar o caráter irredutível da "consciência" ou da "mentalidade" às "condições sociais" de sua produção. As condições sociais, ou seja, os fatores ligados ao "meio ambiente" ou os fatos precedentes não podem "engendrar" os fenômenos da consciência (criações estéticas, descobertas científicas, invenções técnicas), mas somente "condicioná-los". A oposição entre aquilo que "condiciona" e o que "engendra" também foi utilizada por Durkheim, mas em sentido oposto. Para Durkheim, as condições biológicas e mentais dos indivíduos são fatores que podem "contribuir", mas não "determinar" os fatos sociais, enquanto para Tarde os fatores psicológicos ou interpsicológicos são determinantes.

50 O termo "inconsciente" é usado nesse período para descrever processos que resultam de movimentos reflexos ou instintivos, ou seja, trata-se de um "inconsciente cerebral" e não psicológico. Cf. GAUCHET, Marcel. L'inconscient cérébral. Paris: Seuil. 1992.

51 Idem, ibidem, p. 248. 


\section{Moralidade versus ciência social: normal e patológico}

No artigo "Les délits impoursuivis", de 1894, Tarde critica a concepção dos conceitos "normal" e "patológico" de Durkheim ao afirmar que "a criminalidade, segundo o autor, não seria um estado mórbido, mas parte integrante do corpo social" ${ }^{52}$. Interpreta tal afirmação com ironia: se Durkheim estivesse certo, dever-se-ia então comemorar o aumento das taxas de criminalidade em várias nações europeias e lamentar a diminuição do crime na Inglaterra. No ano seguinte, Tarde publica o artigo "Criminalité et santé sociale" com novas críticas a Durkheim, entre as quais se destacam as seguintes: em primeiro lugar, o crime não pode ser normal, pois vai contra a moral do senso comum; trata-se de um fenômeno patológico em si mesmo e não se pode considerá-lo uma condição normal da civilização ${ }^{53}$; em segundo lugar, o crime não está ligado ao aumento da diversidade moral e intelectual ou à liberdade individual, uma vez que o gênio, também produto dessa diversidade, é fruto de um meio moralmente íntegro; finalmente, deve-se desejar a extinção do crime e reformar o sistema judiciário e penal a fim de extingui-lo. Num ímpeto reformista, Tarde aprova até mesmo a censura das artes e da imprensa, pois crê que parte da criminalidade é causada pela imitação de episódios mórbidos divulgados pela imprensa ou de personagens criminosas de obras literárias ${ }^{54}$. Além disso, o "tipo médio" de Durkheim seria um "tipo medíocre", correlato ao rebaixamento intelectual e moral da sociedade, pois não leva em consideração os homens superiores. Para Tarde, a "anormalidade" seria a luta entre "as pessoas de bem e as pessoas do mal" ou aquilo que "impede a harmonia entre os seres orgânicos, psíquicos e sociais de realizarem o fim definido por eles" 55 .

No artigo "Les règles de la méthode sociologique", de 1894, Durkheim afirmara que o critério para a definição do que é "normal" numa

52 TARDE, G. "Les délits impoursuivis". Essais et mélanges sociologiques. Op. cit., p. 169170.

53 "O normal, pois, para uma sociedade, é a paz na justiça e na luz, é a exterminação completa do crime, do vício, da ignorância, da miséria, dos abusos. Sei bem que o perigo dessa definição é uma inclinação muito grande ao espírito de quimera, mas eu a prefiro do que à outra, tão científica que ela julgue ser". TARDE, Gabriel, “Criminalité et santé sociale”, op. cit., p. 151.

54 Idem, ibidem, p. 150.

55 Idem, ibidem, p. 153. 
sociedade não pode ser aquilo que é normal para os indivíduos; aquilo que se deseja ou se acredita ser "bom", do ponto de vista da consciência moral, não coincide necessariamente com o que é "bom" ou desejável em termos sociológicos. Conclui que o "normal", no sentido sociológico do termo, seria o "tipo médio", ou seja, o que perdura no tempo e no espaço, enquanto o "patológico" seria a exceção; o normal seria o que é "geral" e o desvio um traço de morbidez. No artigo "Crime et santé social", publicado no ano seguinte, Durkheim retruca Tarde: o que é normal não é o crime, mas o crime e a pena; por sua vez, o aumento da criminalidade pode ser tanto normal quanto mórbido. Para que o crime não existisse, o "tipo individual" teria que coincidir com o "tipo coletivo", mas, para que a moral avance, ela não pode ser rígida e é por isso que há pessoas com morais distintas ${ }^{56}$.

Os dois autores adotam em relação ao conceito de normal e de patológico posições muito distintas e que têm a ver com os pressupostos ou pontos de partida assumidos por ambos. Tarde parte de uma visão moral ou normativa sobre a sociedade e então formula hipóteses explicativas para o que considera patológico. Ao adotar um modelo universal de moralidade, tende a moralizar a sociologia. Em oposição, Durkheim relativiza a moral social, ou melhor, as distintas morais sociais, a partir do conceito de "tipo social", o que lhe permite escapar ao evolucionismo clássico sem cair no relativismo absoluto. $\mathrm{O}$ exemplo da escravidão é elucidativo nesse sentido: enquanto Tarde considera tal instituição um crime em si mesmo, Durkheim a considera uma instituição "normal" caso esteja de acordo com as condições normais de existência de determinado tipo social.

\section{Sociologia versus ciências sociais}

Depois da publicação de Le Suicide, Tarde publicou a obra Études de Psychologie Sociale, de 1898, composta por um conjunto de artigos já publicados em diversas revistas, mas também um capítulo inédito chamado "La sociologie". O texto é dedicado, em primeiro lugar, a refutar a

DURKHEIM, É. “Crime et santé sociale”, op. cit., p. 518-523. 
importância do "método", pois "aperfeiçoar mais e mais os instrumentos de observação para além de um certo grau é o meio menos seguro de fazer avançar uma ciência" 57 ; ao invés de um "programa de descobertas", uma "boa ideia" seria muito mais importante para inaugurar um novo ramo da ciência. É possível, portanto, que uma "lei geral" seja descoberta antes mesmo que a ciência tenha avançado o suficiente porque o progresso da ciência foge ao controle racional. Daí que uma nova teoria, uma nova "lei" pode perfeitamente anteceder o conhecimento "erudito" produzido pela especialização científica. Tarde utiliza, aliás, o termo "erudição" como sinônimo de "especialização" em oposição à "teoria" ou à "lei geral", enquanto Durkheim identifica três processos científicos distintos: a erudição representa o trabalho de acumulação de casos ou de exemplos empíricos a despeito de uma teoria explicativa; esta, por sua vez, caracteriza as diversas especialidades (sociologia econômica, religiosa etc.) que devem operar, contudo, segundo as mesmas regras do método sociológico a fim de explicar sua causa ou função social; finalmente, a "sociologia geral" se baseia na generalização dos resultados das diversas disciplinas sociais e é uma conquista de longo prazo. Ora, desde Le Suicide, Durkheim afirmava que a especialização disciplinar orientada para a explicação causal ou funcional deveria ser o foco de atenção dos sociólogos, uma vez que a sociologia era uma ciência muito recente para formular leis gerais. Para Tarde, ao contrário, tais leis se aplicam de maneira imediata aos "fatos gerais", que são aqueles que "se repetem ou são suscetíveis de se repetir" ${ }^{58}$.

Em 1898, Durkheim decide não mais responder a Tarde julgando que o debate já havia durado bastante ${ }^{59}$. Contudo, em 1900, escreve o artigo "La Sociologie en France au XIXè. siècle", no qual chega ao ponto de isolar Tarde de todos os autores que contribuíram para o desenvolvimento da sociologia francesa, considerando-o parte de uma reação à ciência ${ }^{60}$. A psicologia social tardeana seria especulativa, pois a imaginação teria um grande papel em suas hipóteses, e os fenômenos contingentes ou acidentais,

57 TARDE, G. "La Sociologie". Écrits de Psychologie Sociale, p. 15.

58 Idem, ibidem, p. 21.

59 Carta de Durkheim a Xavier Léon, 1898. Paris I - Fundo Xavier Léon - FB 612. Conferir também DURKHEIM, É. Textes, 2, Paris: Minuit, 1975.

60 DURKHEIM, É. "La sociologie en France au XIXè. Siècle". Revue Bleue, tomo XIII, 1900, p. 609-613 e 647-652. Cf. site Les Classiques des Sciences Sociales, p. 16. 
que não podem ser expressos por meio de conceitos, seriam fundamentais em sua doutrina.

O confronto final entre os dois autores ocorre alguns anos depois, em 1903, numa palestra de ambos na École des Hautes Études Sociales sobre a relação entre a sociologia e as ciências sociais ${ }^{61}$. Tarde afirma que Durkheim defende a divisão do trabalho para o progresso científico, mas que ele, Tarde, acredita que a psicologia intermental (ou interpsicologia) é necessária à interpretação, definição e desenvolvimento das ciências sociais particulares, uma vez que ela corresponde ao estudo da célula em biologia $^{62}$. O método comparativo, afirma, não pode funcionar se não houver um princípio verdadeiro. Existem dois movimentos no desenvolvimento da ciência: em primeiro lugar, as pesquisas especializadas e as ciências distintas convergem para um ponto e, em seguida, ocorre a síntese dessas ciências distintas. Se, por um lado, as ciências sociais específicas se desenvolveram a partir do método comparativo e evolutivo, caberia à sociologia o trabalho de fazer a "comparação das comparações". Todas as ciências partiram, em seu início, de um ponto de vista objetivista e foram ao longo do tempo se psicologizando. A imitação interpessoal, portanto, não é apenas uma característica distintiva dos fatos sociais e uma explicação para a sua difusão, mas uma lei geral das ciências sociais, cujo papel seria guiar o desenvolvimento das ciências especializadas. Ela é o núcleo da "psicologia intermental", também denominada por Tarde de "sociologia elementar" ou de "sociologia geral", uma vez que ela unifica as ciências sociais, tornando-se uma ideia diretriz para as ciências sociais específicas.

Durkheim, por sua vez, defende a especialização e a construção da sociologia a partir dos resultados das disciplinas sociais específicas: a sociologia não é uma ciência unitária e, por isso, deve-se estudar separadamente cada categoria de fato social. Por outro lado, critica Tarde ao afirmar

61 Infelizmente, não se conhece o registro integral desse debate. A Revue International de Sociologie publicou, em 1904, parte das conferências proferidas por Durkheim e por Tarde. Cf. Revue, p. 83-87, 1904. Uma tradução para o inglês pode ser encontrada em CLARK, Terry. On Communication and Social Influence. Chicago: The University of Chicago Press, 1969. Em 2008, um grupo de autores elaborou, na forma de diálogo, uma versão desse debate baseada na obra de ambos os autores. Eles também promoveram uma encenação em que Bruno Latour fez o papel de Tarde e Bruno Karsenti o de Durkheim. Cf. nota 1.

62 DURKHEIM, É. "La sociologie et les sciences sociales". Revue Internationale de Sociologie, p. 85, 1904. 
que ainda se pensa como na época de Comte, ou seja, como se houvesse um único problema e uma única "lei geral" da socialidade ${ }^{63}$. Por essa via, a sociologia seria uma pura abstração acima das ciências sociais particulares. Para ele, não existe o "fato elementar", como quer Tarde, pois as sociedades são muito complexas e é preciso estudar cada fato concreto em seu próprio tipo social. Tarde pretende formular uma resposta para todos os problemas da sociologia antes mesmo de estudar os fenômenos concretos; sua "síntese" é na verdade uma "especulação filosófica", pois uma verdadeira síntese sociológica só será possível quando as ciências particulares estiverem suficientemente avançadas.

O debate se encerra sem acordo.

\section{Conclusão}

Pode-se perguntar se os dois autores se aproximaram ao longo da vida intelectual ou se, pelo contrário, distanciaram-se. A crer no próprio Tarde, Durkheim se tornara cada vez mais "psicológico" ao longo da década; a crer em Durkheim, Tarde se distanciara cada vez mais dos padrões de validade do conhecimento científico. Do ponto de vista da concepção de ciências sociais, pode-se sugerir que eles se distanciaram cada vez mais, uma vez que Durkheim afirmava seu interesse crescente pela especialização em detrimento da sociologia geral e, Tarde, ao contrário, abandonava as reflexões sobre temas ou problemas específicos - por exemplo, o da criminalidade - para se dedicar à teoria geral ou à sociologia geral. Ou seja, enquanto o primeiro buscava crescentemente causas específicas para fatos sociais determinados, o segundo tendia a sobrevoá-los com fórmulas sintéticas de conjunto destinadas a guiar as pesquisas nas diversas disciplinas sociais. Por outro lado, é fato que Durkheim se distanciara das metáforas organicistas e caminhara ao longo desse período para uma maior ênfase nos problemas ligados à "consciência coletiva" e às "representações coletivas" como expressões de uma dada realidade social. A sociologia seria, portanto, 
uma disciplina da ordem do "mental", mas nesse caso seria sinônimo de "psicologia social" e não de "psicologia individual". Tarde, por sua vez, também pretendia diferenciar a psicologia individual de sua psicologia "interespiritual": a primeira trataria das relações do espírito com a universalidade dos outros seres exteriores enquanto a segunda das relações mútuas entre os espíritos.

A questão da relação entre indivíduo e sociedade ou entre psicologia e sociologia pode ser considerada, portanto, o cerne do debate, mas também defrontaram-se por meio dele duas concepções opostas sobre o funcionamento da vida intelectual. Se, para Tarde, a originalidade intelectual e o progresso da ciência dependem do surgimento de indivíduos superiores e de um regime de meditação solitária, para Durkheim tais processos devem ocorrer cada vez mais por meio de um trabalho coletivo, especializado e através de uma carreira acadêmica. Essa tensão retrata, no plano das ideias, a disputa institucional em torno da mudança estrutural do campo universitário nas últimas décadas do século XIX e, inegavelmente, a posição que cada um deles ocupava naquele momento: o "intelectual livre" e o "professor universitário".

\section{Referências}

BESNARD, Philippe. Durkheim critique de Tarde: des Règles au Suicide. La Sociologie et sa méthode: les Règles de Durkheim un siècle après. Paris: L'Harmmatan, 1995.

BORLANDI, Massimo; BESNARD, Philippe. Contre Durkheim à propos de son Suicide. In: BORLANDI, M.; CHERKAOUI, Mohamed. Le Suicide un siècle après Durkheim. Paris: PUF, 2000.

KARSENTI, Bruno. Retour sur le débat entre Durkheim et Tarde. In: CHAUVIRÉ, Christiane; OGIEN, Albert. La Regularité - habitude, disposition et savoir-faire dans l'explication. Paris: Ed. EHESS, 2002.

LUKES, Steven. Émile Durkheim, su vida y su obra. Madrid: CIS e Siglo XXI, 1984 [1973].

MILLET, Jean. Gabriel Tarde et la Philosophie de l'Histoire. Paris: Vrin, 1970. 
PINATEL, Jean. La pensée criminologique d'Émile Durkheim et sa controverse avec Gabriel Tarde. Revue de Science Criminelle, 1959.

PINTO, Louis. Ne pas multiplier les individus inutilement. Revue Interrogations. Trad. PULICI, Carolina; CONSOLIM, Marcia. Não multiplicar o indivíduo inutilmente. Lua Nova. Revista de Cultura e Política, Cedec, n. 77, 2009.

. Simmel et Tarde dans les années 1900. In: Le Commerce des idées philosophiques. Broissieux: Éd. du Croquant, 2009.

VARGAS, Eduardo V.; LATOUR, Bruno; KARENTI, Bruno; AÏT-TOUATI, Frédérique; SALMON, Louise. The debate between Tarde and Durkheim. Environment and Planning D: Society and Space, v. 26, 2008.

Recebido em abril de 2010.

Aprovado em abril de 2010. 